\title{
La Muerte Fantasmagórica en Las Representaciones de Eva Perón en el Cine y en el Teatro: a Propósito de Evita, la Tumba sin Paz y Eva Perón en la Hoguera
}

\section{Resumo:}

En los años'90 frente a la despolitización de la sociedad menemista el cine y el teatro se ubicaron en un lugar de respuesta política recuperando el significado de un cuerpo como el de Eva Perón. Así Tristan Bauer filmó el documental Evita, la tumba sin paz (1997) y Iris Scaccheri junto a Cristina Banegas llevaron a escena (1994) el poema Eva Perón en la hoguera (1972) de Leónidas Lamborghini. El objetivo del análisis es pensar cómo la muerte se re-significa en ambas obras que proponen registros y dispositivos diferentes. Desde nuestro punto de vista, toda representación enfrenta el problema del contenido de lo real, y en este caso la muerte contiene elementos que rodean el hecho objetivo de la finitud en la relación entre el cuerpo y el sujeto. Para nosotros mientras que Eva Perón en la hoguera le otorga el carácter fantasmagórico al cuerpo de la actriz a través de los gestos y las posturas corporales que reflejan determinadas fotografías, el documental de Bauer toma el cadáver de Evita como material fantasmagórico haciendo hincapié en la utilización del mismo dispositivo: la fotografía. Fotografías que en su mayoría muestran el cadáver y no el registro de la acción política. Para poder analizar cómo se desarrolla esta temática utilizaremos determinadas fuentes históricas basadas en el material de archivo que utiliza el propio documental y las imágenes concentradas en el libro de fotografías- "Eva Perón" editado por la Subsecretaría de la Nación el 4 de junio de 1952- que utiliza la obra teatral. Por otro lado, comprendiendo lo efímero del teatro, trabajaremos con un video completo de una función de la puesta de 1994. También se utilizará cómo fuente una entrevista realizada a Cristina Banegas para este trabajo y material periodístico que den cuenta del impacto social de ambas obras.

Plavras-chave: Embalsamamiento. Dispositivo. Spectrum. Aura.
Jimena C. Trombetta ${ }^{1}$

\begin{abstract}
:
In the 90s, cinema and theatre placed themselves as a political answer against the depoliticization of menemist society, recovering the meaning of Eva Peron's body. That is how Tristan Bauer shot the documentary Evita, la tumba sin paz (1997) and Iris Scaccheri made, with Cristina Banegas, a play based on the poem Eva Perón en la hoguera (1972), by Leónidas Lamborghini. The objective of this analysis is to think how death is re-signified in both works of art, which postulate different artistic registers and devices. From our point of view, all representation faces the problem of the contents of reality, and in this particular case death has elements that surround the objective fact of finity in the relationship between body and subject. For us, while Eva Perón en la hoguera gives the actress' body a phantasmagorical nature through the gestures and body positions showed in certain photographs, Bauer's documentary takes Evita's body as a phantasmagorical material emphasizing the use of the same device: photography. Most of these photographs show the corpse and do not register the political activity. In order to analyze how this theme is developed we use certain historical sources based in the material shown in the documentary and images from the photo book - "Eva Perón" edited by the Subsecretaría de la Nación in June 4th 1952- used in the play. On the other hand, understanding the ephemeral nature of theatre, we work with video footage of the play recorded in 1994. We also use as a source an interview conducted with Cristina Banegas specially for this paper and journalistic material which records the social impact of both works of art.
\end{abstract}

Key-words: Embalm. Device. Spectrum. Aura. 
Con el regreso de la democracia, el cine y el teatro comenzaron a representar nuevamente una figura histórica como Eva Perón. La importancia del peregrinaje del cuerpo proporcionó la necesidad de representar su figura desde las artes y de narrar su muerte de modo simbólico y/o realista, ubicando su perecer en todo momento en un espacio de heroicidad amparada en la religión cristiana. Desde este lugar se resignificó su cadáver embalsamado, y el peso de haber sido considerado un cuerpo proscripto y desaparecido durante la dictadura del ‘ 55 y devuelto definitivamente en 1976 con la condición de ser enterrado a ocho metros bajo tierra en el cementerio de la Recoleta.

En el presente trabajo nos proponemos problematizar la representación de la muerte de Eva Perón en el filme documental Evita, la tumba sin paz de Tristan Bauer y en el poema Eva Perón en la hoguera de Leónidas Lamborghini, llevado al teatro con la interpretación de Cristina Banegas y la dirección de Iris Scaccheri en 1994. El objetivo del análisis es pensar cómo la muerte se re-significa en ambas obras que proponen registros y dispositivos diferentes. Así, evaluaremos la construcción fantasmagórica de Eva Perón en la obra teatral, mediante el cuerpo de la actriz, y en base a la fragmentación del poema que la simboliza desde el martirio. Y por otro lado, observaremos como lo fantasmagórico se perfila en los testimonios que se combinan en el filme y en las escenas de ficción que acompañan la narrativa documental.

Desde nuestro punto de vista, toda representación enfrenta el problema del contenido de lo real, y en este caso la muerte contiene elementos que rodean el hecho objetivo de la finitud en la relación entre el cuerpo y el sujeto. Para nosotros mientras que Eva Perón en la hoguera le otorga el carácter fantasmagórico al cuerpo de la actriz a través de los gestos y las posturas corporales que reflejan determinadas fotografías, el documental de Bauer toma el cadáver de Evita como material fantasmagórico haciendo hincapié en la utilización del mismo dispositivo: la fotografía. Fotografías que en su mayoría muestran el cadáver y no el registro de la acción política.

Para poder analizar cómo se desarrolla esta temática utilizaremos determinadas fuentes históricas basadas en el material de archivo que utiliza el propio documental y las imágenes concentradas en el libro de fotografías- "Eva Perón" editado por la Subsecretaría de la Nación el 4 de junio de 1952- que utiliza la obra teatral. Por otro lado, comprendiendo lo efímero del teatro, trabajaremos con un video completo de una función de la puesta de 1994. También se utilizará cómo fuente una entrevista realizada a Cristina Banegas para este trabajo y material periodístico que den cuenta del impacto social de ambas obras.

Para trabajar sobre el concepto de dispositivo utilizaremos la mirada de Deleuze, quien explica cómo cada dispositivo conlleva rupturas y fragmentaciones en el recorte de la realidad o del objeto a mostrar. En cuanto a lo fantasmagórico en relación a lo fotográfico trabajaremos con el concepto de spectrum propuesto por Barthes, quien explica cómo la fotografía de un rostro es compuesto por un elemento extra -el spectrum- provocado a partir de la afección del espectador. A su vez comprenderemos la problemática de la representación de la realidad desde el punto de vista de Auerbach y de Bill Nichols. Por un lado, Auerbach propone una distinción entre la leyenda, la historia y la teología, y pone en jaque la construcción de la realidad y su contenido religioso. Nichols por su parte establece como la representación de la realidad baraja estructuras, estilos y estrategias en el modo de narrar y alcanzar el objeto.

De esta manera, observamos cómo lo religioso y lo mítico aplicado al cuerpo de la actriz en el teatro y a las imágenes documentales montadas en fragmentos de ficción producidas dentro del filme de Bauer, proporcionan un punto de vista recortado del objeto Eva Perón, que establecen un tipo de sentido específico que cuestiona el modo de representar un personaje histórico. Mientras que la obra teatral se ampara en lo simbólico, y en el parangón del fallecimiento de Eva, con la muerte y la lucha 
de Juana de Arco; el filme de Bauer construye una figura inmaculada desde la momificación de su cuerpo, su peregrinaje y los testimonios que la emparentan con las santas, siempre manteniendo una postura objetiva que le impriman a su material una cuota de "realidad".

\section{Contexto histórico de las creaciones}

Ambas producciones fueron llevadas adelante en el período menemista, una en 1994 (Eva Perón en la hoguera) y la otra en 1997 (Evita, una tumba sin paz). En el primer caso se trata de una puesta teatral dirigida por Iris Scaccheri y encarnada por Cristina Banegas. La actriz nos explicaba que

En el 93 Elbio Vitali estaba por inaugurar la librería Gandhi -que tiene su historia con un montón de gente que había vuelto del exilio como Ana Amado, Nicolás Casullo-. Gandhi aún estaba Montevideo entre Corrientes y Lavalle, pero él se estaba asociando con Losada. Losada, la librería sobre Corrientes era lo que había sido el cine Lorraine. Dentro de ese espacio, en lo que era el superpulman del cine Lorraine, Gandhi-Losada armó el teatro que ahora es el Nudo. Elbio quería hacer un espacio de nucleamiento de personas del arte, de la cultura, del mundo del espectáculo. Él me propuso inaugurar el teatro de la librería. En ese momento yo estaba ensayando Eva Perón en la hoguera que él vio junto a Horacio Gónzalez. Pero la puesta era muy diferente a lo que luego se generó con Iris Scacheri. La puesta con Iris se estrenó entonces en la nueva librería Gandhi. En ese momento yo tuve la sensación y el sentimiento de hacer algo con ese poema como si el fantasma de Eva volviera a esa Argentina del menemato y fuera un fantasma furioso por que encuentra una locura, porque encuentra las injusticias, las partes del poema donde ella habla de los humildes, de los obreros. (BANEGAS, 2014, entrevista para la investigación)

Habría que agregar a la declaración de Banegas también expuesta en la Revista La Maga el 4 de mayo de 1994, que el teatro en los noventa reaccionó políticamente contrario al menemismo. En 1997 aún en período menemista Tristan Bauer había realizado Evita la tumba sin paz que resultó ser el documental con mayor raiting $(26,4)$ de la TV argentina en aquél momento y que Página 12 editó en video en el año 2002 y se incluyó en un ciclo de cine organizado por el Instituto Peronista y la Biblioteca Nacional en el marco de Eva Perón en los libros, 2013. De todos modos, más allá del pasaje del documental por la TV en Canal 13 el 24 de marzo y por su pasaje en el Festival Cinematográfico de La Habana donde recibió el Premio "Coral" al mejor documental. Nos interesaba también destacar bajo el testimonio del guionista Miguel Bonasso para el Página 12 en 1998, el episodio de plagio por parte de Gelblung, quien había utilizado sin permiso quince minutos de documental cambiando a su vez el sentido, alterando el material que describía en aquella nota Bonasso:

Lo que hizo Gelblung esta vez supera sus propios antecedentes. De un documental que tiene en total 50 minutos, robó los 15 minutos fundamentales, donde se encuentran los siguientes materiales originales y absolutamente exclusivos: 1) las fotos que Juan Perón le tomó al cadáver mutilado de su esposa (y que nunca se habían mostrado antes de nuestro trabajo). 2) Las entrevistas exclusivas al fallecido coronel Héctor Eduardo Cabanillas y al restaurador Domingo Tellechea. 3) Datos desconocidos consignados en la narración original que yo escribí y que apenas fueron retocados y estropeados por el guionista de Gelblung. Para poder cambiar, entre otras cosas, la visión histórica y política de la "voz en off" original. El relato de Gelblung 
llega a decir -por ejemplo- que el cadáver de Evita halló por fin la paz cuando la última dictadura militar lo hizo sepultar en la bóveda familiar de la Recoleta, "con la mayor protección y seguridad". Que es lo opuesto a la denuncia de ocultamiento que hace "La tumba sin paz", condenando expresamente a los militares genocidas. 4) Las secuencias de reconstrucción que Tristán Bauer filmó exclusivamente para el documental producido por Ana de Skalon (directora general de South Productions), que fueron barateados con un nuevo montaje y un improcedente viraje al sepia. 5) La música de fondo de algunas escenas (como la del cadáver en el SIE), especialmente compuesta para nuestra producción. (BONASSO, Pagina 12, 15 de abril de 1998)

Nos interesaba exponer este episodio en tanto que Canal 13 se había convertido en opositor del menemismo hacia el final del mandato y canal nueve seguía apoyando el menemismo tanto como lo hacía Gelblung. Desde este punto de vista el cambio de sentido también se ubica al documental en una lógica de protesta y reclamo de justicia sobre todo si entendemos que la elección de la fecha para pasar el documental por el 13 contiene un plus de sentido amparado en asociar la figura de Evita y la idea de una tumba sin paz, a todos los cuerpos desaparecidos el 24 de marzo de 1976. Sucesos que Menem no solo no juzgó si no que se ocupó de dictar los indultos a los militares en el comienzo de su primer mandato (1989-1990)

\section{La muerte en los dispositivos}

Los dispositivos tienen, pues, como componentes líneas de visibilidad, de enunciación, líneas de fuerzas, líneas de subjetivación, líneas de ruptura, de fisura, de fractura que se entrecruzan y se mezclan mientras unas suscitan otras a través de variaciones o hasta de mutaciones de disposición. De esta circunstancia se desprenden dos importantes consecuencias para una filosofía de los dispositivos. (DELEUZE, 1990, p. 156)

El film de Bauer comienza con la narradora en voz off que cuenta la historia sobre el cadáver de Eva Perón entonando su voz hacia lo siniestro del acontecimiento, esa entonación, que poco tiene de objetiva, es afirmada por la primera escena del documental, que prefiere construirse desde la representación del hecho histórico. Esta escena ya plantea un primer desplazamiento proporcionado desde nuestro punto de vista por un dispositivo diferente: el cine de ficción dentro del documental. Bauer construye entonces, una escena dónde lo primero que vemos es un plano medio del cuerpo acostado de Eva Perón, que recuerda al Cristo Muerto de Mantegna por el tipo de angulación que se produce desde el cuerpo, siendo que la cámara sigue posicionada de un modo neutral. Este plano que gira con una leve panorámica muestra una Eva vestida de blanco, levemente tapada por la bandera Argentina, con un rosario en sus manos, con sus uñas color transparente. Ese plano que refleja la religiosidad y el tipo de Eva que construye Bauer, una Eva- Santa es profanada, dice la narradora, por una historia de odio. En ese segundo ingresan a la CGT, mediante un plano detalle de los borcegos de los militares, quienes secuestraron el cuerpo de Eva Perón. El plano posterior confluye ideológicamente, estableciendo una dicotomía de luz y oscuridad con un alto contenido religioso. El lugar donde yace el cuerpo de Eva, un cofre de cristal, es fuertemente iluminado, mientras que los militares permanecen en las sombras. A esta situación propuesta a través de un plano general se suma la imagen de fondo en un poster de la Virgen de Lujan, que refuerza la imagen nacional de la bandera Argentina. La dicotomía entre un bien y un mal sobrenatural, se termina de afirmar en el paneo sobre los rostros de los militares, dejando que el último gesto tomado se conforme como gestus 
político.

Por gestus debe entenderse un complejo de gestos, ademanes y frases o alocuciones que una o varias personas dirigen a una o a varias personas. (...) De la misma manera los gestos y ademanes (...) pueden contener en sí las palabras. Las palabras pueden ser reemplazadas por otras palabras, los ademanes por otros ademanes, sin que eso modifique el gestus, es decir, la actitud subyacente (BRECHT, 1970, p. 26)

Así, el último militar levanta el arma, y en fuera de campo dispara sobre el cristal. Desde esta óptica la muerte se propaga hacia la intención de re-matar la idea de un peronismo nacional.

Bauer le suma a lo sobrenatural un recorrido sobre el Cementerio de la Recoleta donde está enterrada Eva Perón, pero lo hace de noche, para comenzar con la historia de los muertos aristócratas, oligarcas y militares de alto rango que yacen allí, tal como es el caso de Aramburu, responsable del secuestro del cadáver a quien, los montoneros, ajusticiaron en 1970. Una vez que se localiza la tumba de Eva, el documental recurre a mostrar a Eva Perón como "la actriz que el presidente Perón, convirtió en primera dama" (La tumba sin paz, minuto treinta). Aquí se incorpora desde nuestro punto de vista otro dispositivo como lo es el de la memoria o las imágenes-recuerdo definidas por Deleuze cómo imágenes a las que se le aplica una lectura desde el presente o que en términos cinematográficos establecen un recorte de cuadro y una profundidad de campo.

Entonces, en tanto que la selección de la escena de La Pródiga para nombrarla actriz a Eva, apunta a la memoria del argumento de ese film, que muchos han comprendido como una curiosa anticipación a la labor social de Eva Perón. De esta manera la muerte se ubica entre dos bisagras: una muerte embalsamada con movimientos dependientes de la milicia, y una muerte que retorna viva con el plano medio de Eva Duarte encarnando el rol de Julia en el último film de su carrera.

El documental anclado entonces en la idea de forjar el misterio del cadáver en el retorno a la vida, utiliza las fotografías y los testimonios y los materiales de archivo audiovisual en pos de conformar la idea de Eva Santa. Tanto es así que el primer testimonio que se toma e ingresa en ese relato que hasta ese entonces era ficcional, es el de Ana Macri, quien luego de enumerar toda la acción social de Eva y de remarcar actos de conmiseración declara pensar que se trataba de una Santa. Con la intención de mostrar un montaje que plantee un choque entre dos fuerzas, a la escena de Ana Macri acompañada de las imágenes mencionadas con música que dramatiza la escena se le suma la contracara de la oligarquía con la narrativa sobre los negociados acompañada por el jazz, cómo estilo forjado en la cultura anglosajona en la que la aristocracia argentina se anclaba.

Introduciendo el renunciamiento a la vicepresidencia, que desde este documental se debió a la declarada enfermedad, se incorporan nuevas escenas de ficción donde se muestra en el minuto seis a Eva acostada en una cama de hospital con un tubo de oxígeno al lado. Nuevamente el documental recurre a la ficción para narrar situaciones cercanas a la muerte tal como lo es la enfermedad. El cáncer como martirio y Eva como santa permiten hacer permanecer el color blanco en la puesta en escena.

Otro recurso que es interesante ver es cómo se maneja desde la voz de Ana Macri o desde la voz grabada del discurso radial de Eva Perón, la ausencia de su cuerpo en el despacho en el primer caso, y la ausencia de su cuerpo en su alcoba en el segundo caso. La idea de ausencia con una presencia que por sinécdoque la construya también es un modo de darle un carácter espectral al cuerpo. Así, Ana Macri como peronista es parte de Eva; y la voz de Eva también constituye en cierto modo un todo ausente. De esta manera el plano detalle del micrófono radial que vemos mientras la 
escuchamos en off, permanece iluminado mientras habla Eva, y se oscurece cuando su voz calla. Esa metáfora de la muerte es subrayada con la escena siguiente donde vemos a Eva preocupada e ida en un acto político, que la narradora utiliza para declarar que Eva "intuía que le quedaba poco tiempo de vida" (minuto 7:36).

En la misma dirección de seleccionar las imágenes de archivo para establecer a partir del montaje un sentido mítico sobre la muerte es que se incorpora en la secuencia posterior a su rol como acompañante en el coche presidencial por el segundo mandato de Perón, un plano del cielo que anuncia su muerte y la angustia generalizada de los cortejos fúnebres con una copiosa lluvia con truenos. Si bien, los cortejos comenzaron con lluvia, la necesidad de incorporar ese elemento de la naturaleza como punto de partida frente a la muerte prepara el ojo del espectador para seguir en el tono de una Eva sobrenatural, dónde un fenómeno climático y su muerte no puede ser concebida en el documental como una coincidencia. A esa escena específica la prosigue una nueva escena de ficción en la que se panea sobre la habitación de Eva y su cuerpo yacente que vemos de modo parcial, sólo basta un fragmento de su brazo y su mano (la mano de la actriz que la encarnó) con las uñas pintadas de rojo para que "reconozcamos" su cuerpo.

La fragmentación del cuerpo continúa en plano alejados que no dejan divisar su rostro, o en planos de detalle de su rodete, el cambio de color de sus uñas. El cambio de color de las uñas, no es un dato menor dentro del documental, en tanto que da cuenta de que Eva Perón se presentó al pueblo, al medio millón que declara el documental que besó el ataúd, con sus uñas transparentes. Si pensamos que el documental habla de las 26.000 cartas enviadas al vaticano para convertirla en Santa, el pasaje del esmalte del rojo al transparente desliza un sentido de pasaje de mito de femme fatale, propiciado por el antiperonismo al de santa propiciado por el peronismo.

El proceso del embalsamamiento es expuesto como el comienzo de la falta de paz que menciona el documental. Para esto se nutre de una nueva imagen del primer plano del rostro de la actriz que representa a Eva para mostrarla vendada y en pleno proceso químico. El embalsamamiento del cuerpo de Eva, la detención del proceso vivo de su descomposición, la muerte fehaciente de cualquier cambio pretendió detener un tiempo que siguió aconteciendo en el gobierno que perecía, de este modo declara el documental faltaba la llama revolucionaria. Llama revolucionaria que planteará cómo vuelve a encenderse con el secuestro del cadáver. En tanto que trofeo será disputado por peronistas y antiperonistas, provocando un peregrinaje sin fin, que pujaba por perder su embalsamamiento y regresar a su vital descomposición. Claro que el documental comenta el trabajo del nuevo restaurador que ubica nuevamente al cadáver en una muerte radical: un luto perpetuo, una pieza de museo. Es allí donde la descorporización se politiza en tanto que el cuerpo pasa a ser insignia, y su prohibición el reforzamiento del mito.

En ese tono el documental sigue narrando el peregrinaje del cadáver incorporando a la historia elementos de la literatura, más precisamente mencionando el cuento de Rodolfo Walsh Esa mujer, para develar el contenido real del cuento a través de presentar la historia del Teniente Coronel Moori Köening. Lo siniestro se ubica en el relato del Coronel Cabanillas, quien cuenta la necrofilia de Moori Köening y le da un valor de verdad, de real a lo narrado por Walsh en el cuento. Lo que nos interesa relatar es como el cuerpo muerto de Eva es visto como una muñeca, como un objeto. Y cómo esa objetivación de Eva se carga de un contenido místico en dónde la preservación del cadáver y sus posteriores profanaciones darían por resultado una serie de hechos misteriosos. Esto nuevamente le da un carácter sobrenatural al cuerpo de Eva como objeto y al signo Evita separadamente.

Hasta ahora hemos analizado el carácter del dispositivo cinematográfico comprendiendo 
como juega a partir de su práctica documental con imágenes que pretenden tener una cuota de realidad, incluso si se arman de modo ficcional. En este sentido, el cine toma la muerte para generar una idea de retorno constante, para que recobre una cuota de lo vivo incluso desde la fantasmagoría que implica ver un cuerpo o un rostro en cine, y mucho más si se trata de alguien ya fallecido. Así podemos ver como los planos descriptos proponen una construcción de la muerte real que se supedita a la narrativa, a su mimesis. Estos planos y montaje estarán llenos de indeterminaciones espacio/ temporales. El otro dispositivo que contiene un elemento que retorna lo muerto en vida o en movimiento y cambio temporal es el dispositivo teatral, en el cuál se suma el convivio (Dubatti, 2010) entre el cuerpo en escena y el espectador. Con la intención de tener en cuenta la propia característica teatral también nos interesa analizar Eva Perón en la hoguera, el poema de Leónidas Lamborghini, que fue llevado a escena en 1994 por Cristina Banegas.

En este caso la muerte es tomada poéticamente y ninguna intención de establecer escenas de lo real se incorporan a la puesta en escena. La escenografía se reducía a una mesa, dónde se hallaba un libro de imágenes que contraían la memoria de la vida, obra y muerte de María Eva Duarte de Perón en una serie de fotografías que no se mostraban a público pero que la actriz Cristina Banegas trabajaba afectivamente y componía el personaje Eva, a partir de la representación de los gestos de esas fotografías. De este modo en la entrevista que pudimos realizar nos comentaba la importancia de aquél material, el cuál tenía marcado con momentos de la obra que referían a tal o cuál foto.

El poema en su texto establece una relación de muerte simbólica que remite a la muerte de Juana de Arco, en la hoguera y que se deja entrever en los gestos de Cristina Banegas y en los movimientos de su cuerpo, en algunos momentos espasmódicos y fragmentados. De todas maneras, si bien nos remitimos a la idea de un cuerpo dentro de una hoguera, esa hoguera en este caso confluye con la actividad política del personaje histórico Eva Perón. Y en este sentido la ‘puesta se ubica en ese lugar. La actriz siempre vestida con el traje sastre, en este caso color bordó, y el rodete, en este caso del color del pelo de la actriz, castaño oscuro, representa como mencionamos posturas y gestos de la vida política. Entonces podemos ver como el primer gesto antes de comenzar a expresar el texto es de dadora hacia el pueblo, en un grito de entrega. Ese primer gesto mudo, que repetimos, se aúna en un grito de dolor y entrega, permanece en silencio hasta el segundo espacio en que Banegas comienza a decir el poema, ahora en otro espacio indeterminado que refleja el despacho presidencial. La muerte en este caso es vista desde lo fantasmagórico del cuerpo, del entrecruzamiento de auras entre el cuerpo ausente que trata de reflejar Banegas y su aura presente. Parte de ese entrecruzamiento se arma desde la voz, parte mínima del cuerpo que está encargada de transmitir también el no-lugar en que se halla el personaje. La idea de un no-lugar también refleja la idea de la hoguera como un espacio de pasaje de la vida a la muerte. En este sentido, Banegas expresa con su voz ese pasaje matizando los gritos y los susurros como un vaivén deboto, que le adjunta a la hoguera la idea política de la entrega hacia el pueblo

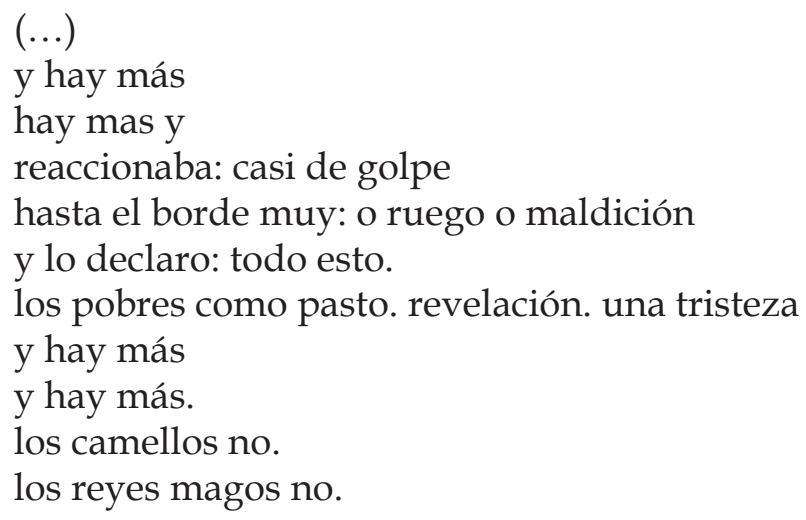


los pobres no: como pasto.

y lo declaro

y lo sentí:

todo esto cambiará.

o ruego

o maldición:

o las dos cosas. (LAMBORGHINI, 1972, poema III, s/p)

Esas hogueras dirá Nicolás Casullo en el programa de mano son el reflejo del fracaso de la historia.

En Eva Perón... nos enfrentamos ya a la ruina de un tiempo: el de Evita no un lenguaje del inconsciente, a un monólogo alusinado, al balbuceo de un oprimido. Si posiblemente, cuando hoy la obra reabre su eterno gesto inédito, nos encontramos con un texto de locura frente a los restos de una historia. Más precisamente, al desvarío de lo histórico cuando deja de protegernos con sus "sentidos" y "objetivos" a obedecer y a alcanzar la voz de Evita, en todo caso, es esa irrupción de la catástrofe en la historia. (CASULLO, 1994, Programa de mano)

Por otro lado la puesta utiliza las fotografías, esa idea del retorno de lo muerto, para darle movimiento a gestos sostenidos que reflejan un momento determinado cómo lo puede ser el 17 de octubre de 1945. Al gesto peronista de los brazos levantados y la V de la victoria, se le suma la integración de la voz de Perón que le dictamina encargarse de la misión a Eva Perón de convocar a la Plaza de Mayo. Esa nueva voz también funciona como la idea de una fotografía, como la idea del retorno de lo muerto.

(...) un: el líder él

su palabra. un mensaje: encárgate. encárgate.

la hora. los golpes. las sombras. la llama: arder.

esto: la traición

muchos.

esto: la cobardía

muchos.

esto: una gran luz. la lealtad muchos: que conservo. anduve. me largué:

de puerta en puerta por la gran por la ciudad. bajo el cielo: la llama.

en ese.

arriba: los comunes. los eternos. los pilatos lavándose. los golpes.

descendí: una gran luz que conservo. los corazones: el muestrario.

los humildes que laten generosamente. descendí. sentí arder. una gran que

conservo. una luz: de allí vino. los humildes que laten: el muestrario.

generosamente. de allí vino: en ese.

a medida que: las puertas.

a medida que: el muestrario. bajo el cielo: arder. arder.

aquellos días lo tuvieron: el líder él. su palabra. su mensaje:

los trabajadores: encárgate.

los descamisados: encárgate. encárgate.

el pueblo únicamente: de allí vino. arriba: los pilatos lavándose:

mi calvario. la hora.

arriba: ¡esa es! ¡esa es! mi bautismo: cada.

¡esa es! ¡esa es!

los puñetazos. esto: cada golpe morir. 
¡esa es! ¡esa es!

esto: cada golpe

nacer.

(LAMBORGHINI, 1972, poema VI, s/p)

Así se atribuye a Evita el calvario de convencer al pueblo en el comienzo del peronismo. De este modo, se establecen binomios que se contradicen y se unen en el poema que refuerzan la construcción de la voz, del cuerpo y del espacio. Toda la puesta es estar y no estar, del escenario al palco político, de ser un cuerpo actoral en escena a buscar a Eva Perón dentro de ese cuerpo. Las búsquedas del cuerpo que cambian de una emoción a la otra se construyen por pequeños interludios corporales que destacan desde la voz y desde el cuerpo, además del pasaje de un poema a otro, la idea de una animalización o la búsqueda de una emoción visceral. Esto se puede ver entre el verso en el que se destaca la muerte del pueblo, y la búsqueda de justicia. El primer gesto, ese grito silencioso se retoma en el final, ya con sonido. En este sentido el apagón va sobre ese gesto y desde ese lugar se congela, se detiene ese gesto, se lo convierte en fotografía.

La intención de narrar los gestos y las fotografías que se imitan desde la composición gestual de la actriz apunta a mostrar una idea de congelamiento que niega el embalsamamiento y congela otro perfil político. La puesta busca un cuerpo activo, y deja de lado el cuerpo oficial del embalsamamiento. Así como sostiene Casullo,

El decir fragmentado, auto destructivo, de violencia que implosiona en los labios y en el cuerpo de esa mujer política, dan cuenta de los residuos de una historia, que posiblemente recién ahora, frente a la escena teatral, podemos entender en su más impronunciable profundidad. Como ella dice: "fue mi país". Eva Perón... nos saca del mito Evita, no para reponernos de aquella mujer revolucionaria la funcionalidad plástica de su cadáver, sino para sustraernos absolutamente de esa tentación.

(CASULLO, 1994, Programa de mano)

Así el documental denuncia el embalsamamiento, y la proscripción histórica de su figura Y la obra teatral proporciona una nueva lectura que la quita directamente del lugar plástico, de la idea de pieza de museo. Para ubicarla en un espacio/tiempo fragmentario propuesto desde el lenguaje que se trasunta en el movimiento, voz y gesto de la actriz.

\section{Algunas conclusiones}

Hemos visto como el cine y el teatro toma la figura de Eva para formular imágenes-recuerdos, elementos de la memoria que reutilicen el contenido simbólico que yace en el cuerpo de Eva Perón embalsamada. El embalsamamiento como mencionamos funcionó como una ubicación corporal de pieza de museo, con un aura en términos de Walter Benjamin irreproducible que tanto el cine como el teatro renuevan en sus narraciones. Lo que el cine y el teatro hacen, a pesar de ser dos dispositivos de lenguaje diferentes, el primero permanente, reproducible y el segundo efímero, es quitar a Eva del cuerpo, descorporizarla del cadáver embalsamando para recobrar el recuerdo vivo, convirtiendo su cuerpo ausente- en cuerpo presente mediado por actrices.

A su vez, podemos observar que mientras que el filme de Bauer compone el embalsamamiento como el mayor hecho siniestro, el poema de Lamborghini toma la hoguera como el elemento que 
libera o retoma la furia revolucionaria del contenido simbólico de la figura de Eva Perón, pero lo hace desde el fracaso político del menemismo.

\section{Referencias}

AUERBACH, Erich. Mimesis. La representación de la realidad en la literatura occidental. México: F.C.E., 1996.

BONASSO, Miguel. El parche negro de Gelblung. Contratapa, p. 12, 15/04/1998

BRECHT, Bertolt, Escritos sobre teatro (Selección de Jorge Hacker - Traducción de Nélida Mendilaharzu de Machain), Buenos Aires: Ediciones Nueva Visión, 1970.

CASULLO, Nicolás. Reflexiones sobre el espectáculo teatral “Eva Perón en la hoguera”. Programa de mano, 1994.

DELEUZE, Gilles, ¿Qué es un dispositivo? In Michel Foucault, filósofo. Barcelona: Ed. Gedisa, 1990, p.155.

DUBATTI, Jorge, Filosofía del teatro I. Convivio, experiencia, subjetividad. Buenos Aires: Atuel, 2010.

LAMBORGHINI, Leónidas, “Eva Perón en la hoguera”, en Partitas. Buenos Aires: s/e, 1972.

NICHOLS, Bill, La representación de la realidad. Cuestiones y conceptos sobre el documental. Barcelona: Paidós, 1997. 